\title{
Reliability improvement and loss reduction in radial distribution system with network reconfiguration algorithms using loss sensitivity factor
}

\author{
Parasa Sushma Devi ${ }^{1}$, Dasari Ravi Kumar ${ }^{1}$, Kiran Chakravarthul a ${ }^{2}$ \\ ${ }^{1}$ Department of Electrical and Electronics Engineering, Vallurupalli Nageswara Rao Vignana Jyothi Institute of Engineering and \\ Technology, Jawaharlal Nehru Technological University Hyderabad, Hyderabad, India \\ ${ }^{2}$ Department of Electronics and Instrumentation Engineering, Department of Electrical and Electronics Engineering, Vallurupalli \\ Nageswara Rao Vignana Jyothi Inst itute of Engineering and Technology, Hyderabad, India
}

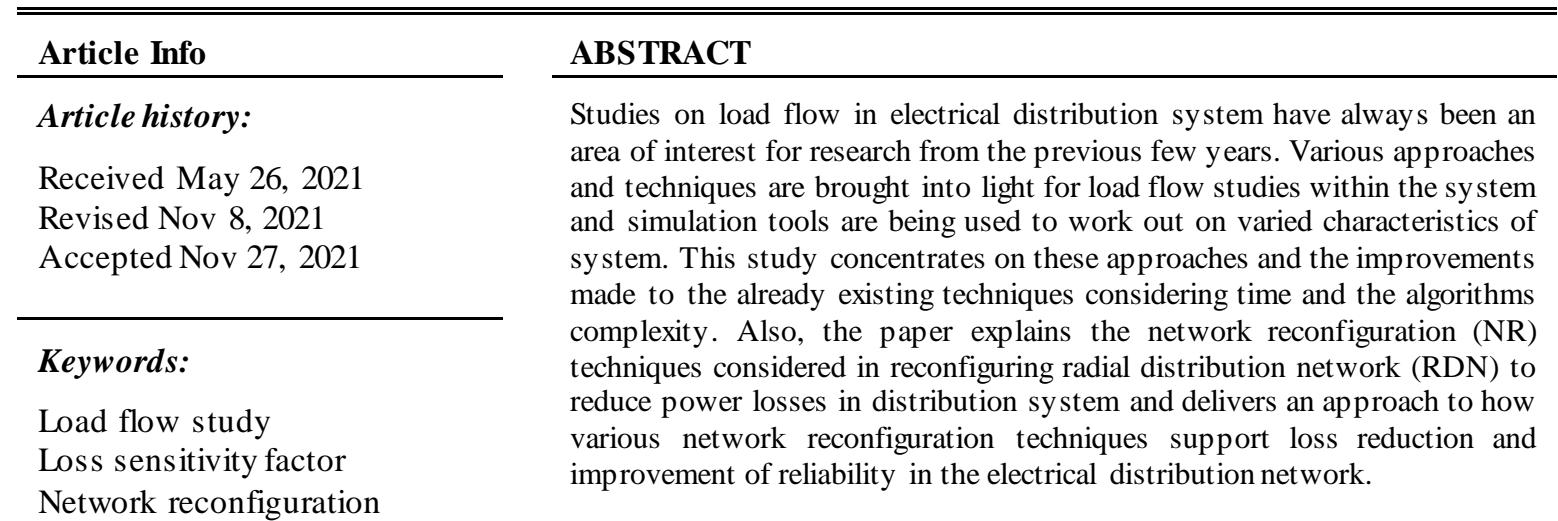

This is an open access article under the $\underline{C C B Y-S A}$ license.

Radial distribution system

Reliability indices

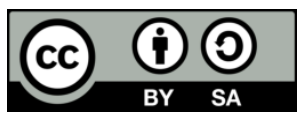

\section{Corresponding Author:}

Parasa Sushma Devi

Department of Electrical and Electronics Engineering, Vallurupalli Nageswara Rao Vignana Jyothi, Institute of Engineering and Technology, Jawaharlal Nehru Technological University Hyderabad

Hyderabad-500090, India

Email: sush1634@gmail.com

\section{INTRODUCTION}

In distribution systems, finding out the best possible status of placing the sectionalizing switch (SS) is determined by the network reconfiguration (NR) which is done to reduce losses and to improve reliability. NR is the process of changing the open or close condition of sectionalizing switches and tie switches in a distribution system for adjusting the network topology and improve distribution system performance based on the limitations considered [1]. Generally, the loss reduction, voltage enhancement, and load balancing are the main objectives of NR [2]. Reconfiguration of the system leads to reduction in power loss in distribution system [3]. Distribution network reconfiguration (DNR) attained considerable focus in the past few years. Most of the techniques considered for the NR process used heuristic, mathematical programming or approximation techniques. DNR using fireworks algorithm, simulated annealing, genetic algorithm based approaches, and particle swarm optimization (PSO) have also been considered.

Ascertained a survey in DNR methods, is considered in [4]. An appropriate survey about encoding techniques for network on different meta-heuristic DNR approaches is explained in [5]. A short idea on various NR techniques are explored in [6]. A brief summary of DNR methods with heuristic approaches is explained in [7]. In [8], [9], analysis of population-based artificial intelligence (AI) techniques to DNR is given. Moreover, these population-based AI techniques include the PSO, genetic algorithm (GA), and ant 
colony optimization (ACO) only. Lavorato et al. [10] given a literature review on DNR techniques proposing radiality constraints. Brief review on classification of DNR approaches with single or multi-objectives is explained in [11]. A review on loss minimization in distribution systems is presented in [12]. Some patents on power distribution NR (PDNR) methods are viewed in [8], [13]-[17].

The meta-heuristic is usually referred to as an approach to resolve the NR issues. Various metaheuristic algorithms are proposed within the works of literature for resolving these problems like GA, PSO, fireworks algorithm (FWA), cuckoo search algorithm (CSA), ACO, shuffled frog leaping algorithm (SFLA) [18]-[22] and runner-root algorithm (RRA). Particularly, SFLA for resolving the problems in optimization mainly because of high accuracy in local optimal searching [23], [24].

New technologies for NR are suggested in [25], [26] as they are limited with the results and additional cost to be imposed on the system. But the NR algorithm based on loss sensitivity factor (LSF) condition, there would not be any imposition of additional cost on the system. NR is done only by altering the power flow path in the systemwhich would be more beneficial on the today's power systemenvironment.

This paper proposes a novel NR algorithm that will minimize the losses and enhances the reliability in the distribution system. The algorithm adopts various LSF conditions and simulated using MATLAB environment. The reason of a load flow analysis (LFA) is to determine power loss values, reliability, and voltage profile. Algorithm is developed such that all the constraints considered are satisfied and to find best possible way of having the sectionalizing switch so that the power flow is altered and radiality of the system is maintained.

\section{PROBLEM FORMULATION}

The key issues addressed in this work are voltage profile enhancement, reduction in power loss, and reliability improvement by NR. Voltage must be kept between the specified minimum and maximum tolerance limits. Radial distribution systems (RDSs) are the only options for getting from the feeder to the customer. With network reconfiguration, power losses and performance indices should be reduced. It is accomplished by picking the configuration that produces the minimal power losses, the lowest failure indices, and satisfies a set of requirements from among all feasible configurations. The objective of minimizing power loss and improving reliability is achieved by considering the following constraints and minimizing real power loss and reliability indices.

- Node voltage constraint:

$$
\mathrm{V}_{\mathrm{i}, \min } \leq \mathrm{V}_{\mathrm{i}} \leq \mathrm{V}_{\mathrm{i}, \max }
$$

where $V_{i, \text { min }}$ is the minimum allowable root mean square (RMS) voltages at node $i, V_{i, \max }$ is the maximu $\mathrm{m}$ allowable RMS voltages at node i.

- Power losses and reliability indices:

$$
\begin{aligned}
& 0<\mathrm{P}_{\mathrm{L}}, \mathrm{Q}_{\mathrm{L}} \leq \mathrm{P}_{\mathrm{Lb}}, \mathrm{Q}_{\mathrm{Lb}} ; \quad 0<S A I F I \leq(\mathrm{SAIFI})_{\mathrm{b}} ; \quad 0<\mathrm{SAIDI} \leq(\mathrm{SAIDI})_{\mathrm{b}} ; \quad 0<\mathrm{CAIDI} \leq(\mathrm{CAIDI})_{\mathrm{b}} ; \\
& 0<\mathrm{ASUI} \leq(\mathrm{ASUI})_{\mathrm{b}} ;
\end{aligned}
$$

\section{LOAD FLOW AND NETWORK RECONFIGURATION ALGORITHMS}

\subsection{Load flow analysis (LFA)}

Teng [27] describes the bus injection to branch current (BIBC) and branch current to bus voltage (BCBV) matrices. They'll lay out the distribution network. To determine the relationship between bus current injections and branch currents, the bus injection to branch current matrix is employed. To determine the relationship between branch current and bus voltage, the branch current to bus voltage matrix is employed. For load flow analysis, the distribution load flow technique with forward and backward sweep algorithms used in [28] is utilized because it has greater advantages such as efficiency and high convergence.

\subsection{Reliability evaluation}

Load point indices are considered in the evaluation of system reliability which is stated by Average annual outage time $(U)$, Average failure rate $(\lambda)$ used in [29],

$$
\lambda_{\text {sys }, \mathrm{i}}=\sum_{\mathrm{k} \in \mathrm{S}} \lambda_{\mathrm{k}}
$$




$$
\mathrm{U}_{\mathrm{sys}, \mathrm{i}}=\sum_{\mathrm{k} \in \mathrm{S}} \lambda_{\mathrm{k}} \mathrm{r}_{\mathrm{k}}
$$

Average outage time ( $r$ )

$$
r_{\text {sy }, i}=\frac{U_{\text {sys }, i}}{\lambda_{\text {sys }, i}}
$$

where $\lambda_{\text {sys,i }}$ represents the failure rate at the ith load point, $U_{\text {sys,i }}$ represents the annual outage duration at the ith load point, $\mathrm{r}_{\mathrm{sys}, \mathrm{i}}$ kare represent the failure rate and average repair time of the $\mathrm{k}^{\text {th }}$ distributor segment, and $\mathrm{S}$ represents the set of distributor segments connected in series until the $\mathrm{i}^{\text {th }}$ load point. Billinton and Allan [30] lists the performance indexes that are commonly employed.

\subsection{Loss sensitivity factor (LSF)}

It is stated as the linearization of a nonlinear equation that is centered on original operating point, resulting in smallest number of solution spaces. LSF is defined as active power loss (APL) variation w.r.t real power [31] at $\mathrm{i}^{\text {th }}$ bus and is given by (4).

$$
\propto_{i}=\frac{\partial P_{\text {Loss }}}{\partial P_{i}}=2 \propto_{i i} P_{i}+2 \sum_{\substack{j=1 \\ j \neq i}}^{n}\left(\propto_{i j} P_{j}-\beta_{i j} Q_{i j}\right)
$$

\subsection{Network reconfiguration algorithms}

The following network reconfiguration algorithms (NRAs) are examined in this study. The proposed NRA's are considered in the search for better switching combination apart from decreasing losses, it improves voltage stability, voltage profile and network reliability by considering a tie switch and its neighboring sectionalized switches (SS) as shown in Figure 1, one at each time, and the process continues till it finds no improvement in voltage stability and minimization of power loss and performance indices. A LFA should be performed to confirm that the performance indices and losses are minimized before approving the reconfiguration. If not the reconfiguration must reset to the before condition.

\subsection{LSF based network reconfiguration algorithm}

- Step 1 : Read the bus data, line data, distribution system probability, and set the flag to zero for all tie switches.

- Step 2 : Using the BIBC and BVBC matrices, run the distribution load flow and compute the node voltages, actual power losses, reactive power losses, and reliability indices.

- Step 3 : The voltage must remain within the required range. $V_{i, \min } \leq V i \leq V_{i, \max }$ i.e. within the $6 \%$ of rated voltage; $0.94 \leq V i \leq 1.06$, if yes then go to step 11 .

- Step 4 : Determine the LSF difference between the tie switches' end nodes $\mathrm{k}$ and $\mathrm{m}$ with the zero flag. The tie switch with the maximum LSF difference is selected.

- Step5 : Determine whether the LSF at the $\mathrm{k}^{\text {th }}$ node is greater than the $\mathrm{m}^{\text {th }}$ node. If yes, proceed to step 7.

- Step 6 : Open the sectionalizing switch between k and k-1.

- Step 7 : Open the sectionalizing switch between $\mathrm{m}$ and $\mathrm{m}-1$.

- Step 8 : Connect the tie switch and set the flag to 1 .

- Step 9 : Verify that all tie switches flags are equal to 1 , then go to step 10.

- Step 10 : Determine the power losses. If not $0<\mathrm{P}_{\mathrm{L}}, \mathrm{Q}_{\mathrm{L}} \leq \mathrm{P}_{\mathrm{Lb}}, \mathrm{Q}_{\mathrm{Lb}}$; then go to step 2

- Step 11 : Calculate the system average interruption frequency index (SAIFI), system average interruption duration index (SAIDI), average system unavailability index (ASUI), and customer average interruption duration index (CAIDI) dependability indices. If not $0<S A I F I \leq(S A I F I)_{\mathrm{b}}$; $0<S A I D I \leq(S A I D I)_{\mathrm{b}}$; $0<C A I D I \leq(C A I D I)_{\mathrm{b}} ; 0<A S U I \leq(A S U I)$ b; Move on to step 2 .

- Step 12 : Print the values of $|\mathrm{V}|$, LSF, $\mathrm{P}_{\mathrm{L}}, \mathrm{Q}_{\mathrm{L}}, \mathrm{SAIDI}, \mathrm{SAIFI}, \mathrm{ASUI}$, and CAIDI.

\subsection{Algorithm conditions considered for network reconfiguration of distribution system}

Maximum LSF difference, considering only adjacent sectionalizing switch; minimum LSF difference, considering only adjacent sectionalizing switch; maximum LSF difference, considering the SS which gives minimum losses; minimum LSF difference, considering the SS which gives minimum losses. 


\section{RESULTS AND ANALYSIS}

The LFA and network reconfiguration algorithms of radial distribution system are implemented in MATLAB. Power loss is calculated for various network reconfiguration algorithms and analysis is done. Our proposed methods are compared with existing methods in literature.

\subsection{Power loss of 33-bus RDS base configuration}

The load flow algorithm is applied to 33-bus radial distribution system shown in Figure 1 using MATLAB programming. Power loss values are shown in Table 1. Tables 2 and 3 show the performance indices and obtained results of voltage magnitude, phase angle, and LSF of 33-Bus RDS for base configuration.

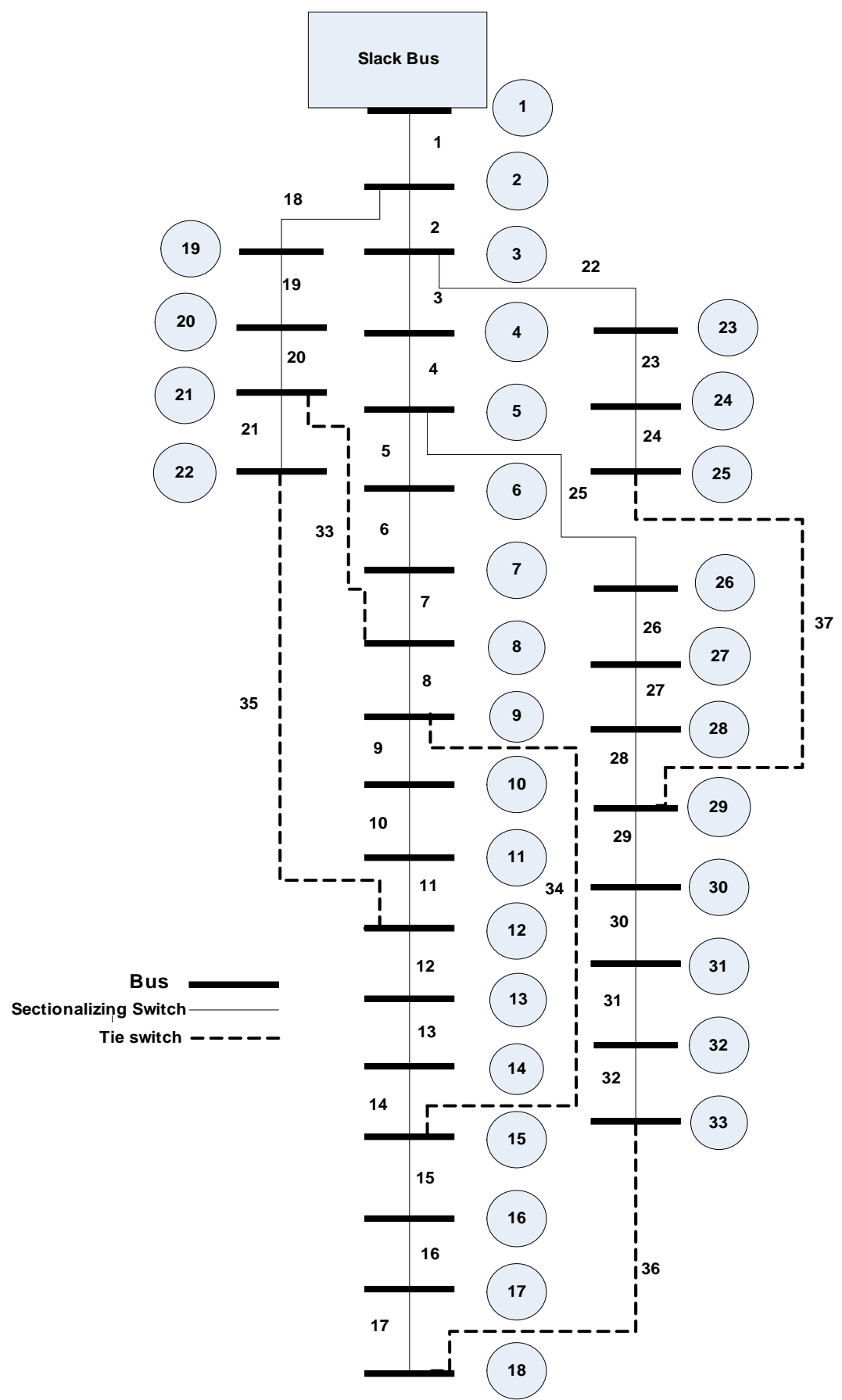

Figure 1. Line diagram of 33 bus RDS 
Table 1. Power loss values for base configuration of 33-bus RDS

\begin{tabular}{cc}
\hline Parameter & Simulated Result \\
\hline (APL) (kW) & 202.6650 \\
(RPL) (kVar) & 135.1327 \\
(TPL) (kVA) & 243.5856 \\
\hline
\end{tabular}

Note: APL: active power loss, RPL: reactive power loss, TPL: total power loss

Table 2. Performance indices of 33 bus RDS-base configuration

\begin{tabular}{ccccc}
\hline INDEX & SAIDI & SAIFI & CAIDI & ASUI \\
\hline Value & 2.4126 & 2.0436 & 0.8470 & $2.3328 \mathrm{e}-4$ \\
\hline
\end{tabular}

Table 3. Converged values of, phase angle, voltage magnitude and LSF before NR

\begin{tabular}{cccccccc}
\hline Bus No. & $\begin{array}{c}\text { Voltage } \\
\text { Magnitude (p.u) }\end{array}$ & $\begin{array}{c}\text { Phase } \\
\text { Angle (p.u) }\end{array}$ & LSF & Bus No. & $\begin{array}{c}\text { Voltage } \\
\text { Magnitude (p.u) }\end{array}$ & $\begin{array}{c}\text { Phase } \\
\text { Angle (p.u) }\end{array}$ \\
\hline 1 & 1.00000 & 0.00000 & 0.005195100 & 17 & 0.91376 & -0.00847 & 0.000850048 \\
2 & 0.99703 & 0.00025 & 0.004314776 & 18 & 0.91316 & -0.00864 & 0.000127706 \\
3 & 0.98295 & 0.00167 & 0.010517832 & 19 & 0.99651 & 0.00006 & 0.002113020 \\
4 & 0.97548 & 0.00282 & 0.012981822 & 20 & 0.99293 & -0.00111 & 0.000450873 \\
5 & 0.96808 & 0.00398 & 0.016555203 & 21 & 0.99222 & -0.00144 & 0.002336018 \\
6 & 0.94970 & 0.00233 & 0.009489519 & 22 & 0.99159 & -0.00180 & 0.004097798 \\
7 & 0.94621 & -0.00168 & 0.009826005 & 23 & 0.97936 & 0.00113 & 0.004748190 \\
8 & 0.94137 & -0.00105 & 0.002870083 & 24 & 0.97269 & -0.00041 & 0.003705224 \\
9 & 0.93511 & -0.00233 & 0.000043342 & 25 & 0.96937 & -0.00118 & 0.008270925 \\
10 & 0.92930 & -0.00342 & 0.001042876 & 26 & 0.94777 & 0.00302 & 0.003117823 \\
11 & 0.92844 & -0.00329 & 0.000119320 & 27 & 0.94521 & 0.00400 & 0.003441634 \\
12 & 0.92694 & -0.00309 & 0.000979896 & 28 & 0.93378 & 0.00545 & 0.006031129 \\
13 & 0.92083 & -0.00469 & 0.003196831 & 29 & 0.92556 & 0.00681 & 0.002094279 \\
14 & 0.91857 & -0.00606 & 0.001365677 & 30 & 0.92201 & 0.00864 & 0.001629334 \\
15 & 0.91715 & -0.00672 & 0.001161101 & 31 & 0.91785 & 0.00717 & 0.003172595 \\
16 & 0.91579 & -0.00712 & 0.001844113 & 32 & 0.91694 & 0.00677 & 0.003340355 \\
& & & & 33 & 0.91665 & 0.00664 & 0.003645279 \\
\hline
\end{tabular}

\subsection{Comparison of network reconfiguration algorithms}

Load flow analysis and network reconfiguration Algorithm 1 is performed on 33-bus RDS with MATLAB and the output obtained is analyzed. From the obtained results of 33-bus RDS for base case shown in Table 1, Active power loss obtained is $202.6 \mathrm{~kW}$. The LSF difference between $25-29$ is largest, and hence initially this tie-s witch is closed. As LSF of 25 is higher than LSF of 29, the switch between 29-28 is opened. Then, the active power loss is $172.0631 \mathrm{~kW}$.

In NRA 1, the next switch (tie) closed is $9-15$, continue the process and solution are to open switch in branch 15-14. Now the real power loss is $230.9624 \mathrm{~kW}$. Next switch to be closed is $18-33$, then repeat the process and the switch to be opened is between 33-32. The power loss value for this switch is $164.5364 \mathrm{~kW}$. The procedure is repeated till final optimal configuration is achieved. Thus, final total real power loss is $164.5364 \mathrm{~kW}$ after reconfiguration with NR Algorithm 1. Power loss values after NRA 1 are tabulated in Table 4 respectively.

Table 4. APL and RPL at different tie switches using algorithm 1 [30]

\begin{tabular}{cccccc}
\hline Power Loss & Tie Switch (25-29) & Tie Switch $(9-15)$ & Tie Switch (18-33) & Tie Switch (22-12) & Tie Switch (21-8) \\
\hline APL (kW) & 172.06 & 166.14 & 155.62 & 139.58 & 137.53 \\
RPL (kVar) & 117.06 & 112.98 & 104.3 & 94.18 & 113.48 \\
\hline
\end{tabular}

Figure 2 represents the line diagram of reconfigured 33 bus RDS using NRA 1. In the second algorithm minimum LSF difference is considered in order to operate the tie switches. The LSF difference between 18-33 is smallest, so first this tie switch is closed. As LSF of 18 is less than the LSF of 33, the switch in between 33-32 is opened. Here, APL is $198.7574 \mathrm{~kW}$.

In NRA 2, next tie switch 21-8 is closed is, then repeat same process and solution is to open switch in branch 8-7. Now the total active power loss is $127.1754 \mathrm{~kW}$. Next close the tie switch $9-15$, then continue the process and open switch in between 15-14. The power loss value for this switch is $160.8898 \mathrm{~kW}$. The same process is repeated until optimal configuration is achieved. Thus, final active power loss is $127.1754 \mathrm{~kW}$ after reconfiguration with NR Algorithm 2. Power loss values after network reconfiguration Algorithm 2 are given in Table 5. Figure 3 represents line diagram of reconfigured 33 bus RDS using NRA 2. 
The third algorithm considers the maximum LSF difference as well as the sectionalizing switch that results in the minimum amount of losses. Because the LSF difference between 25 and 29 is the greatest, this switch is closed. Because the LSF of 25 is greater than the LSF of 29, the switch between 29 and 28 is opened, and the process of calculating the power loss at each SS continues. The optimum case is a sectionalizing switch that produces the least amount of losses. In this case, the power loss after accounting for all switches is $155.17 \mathrm{~kW}$.

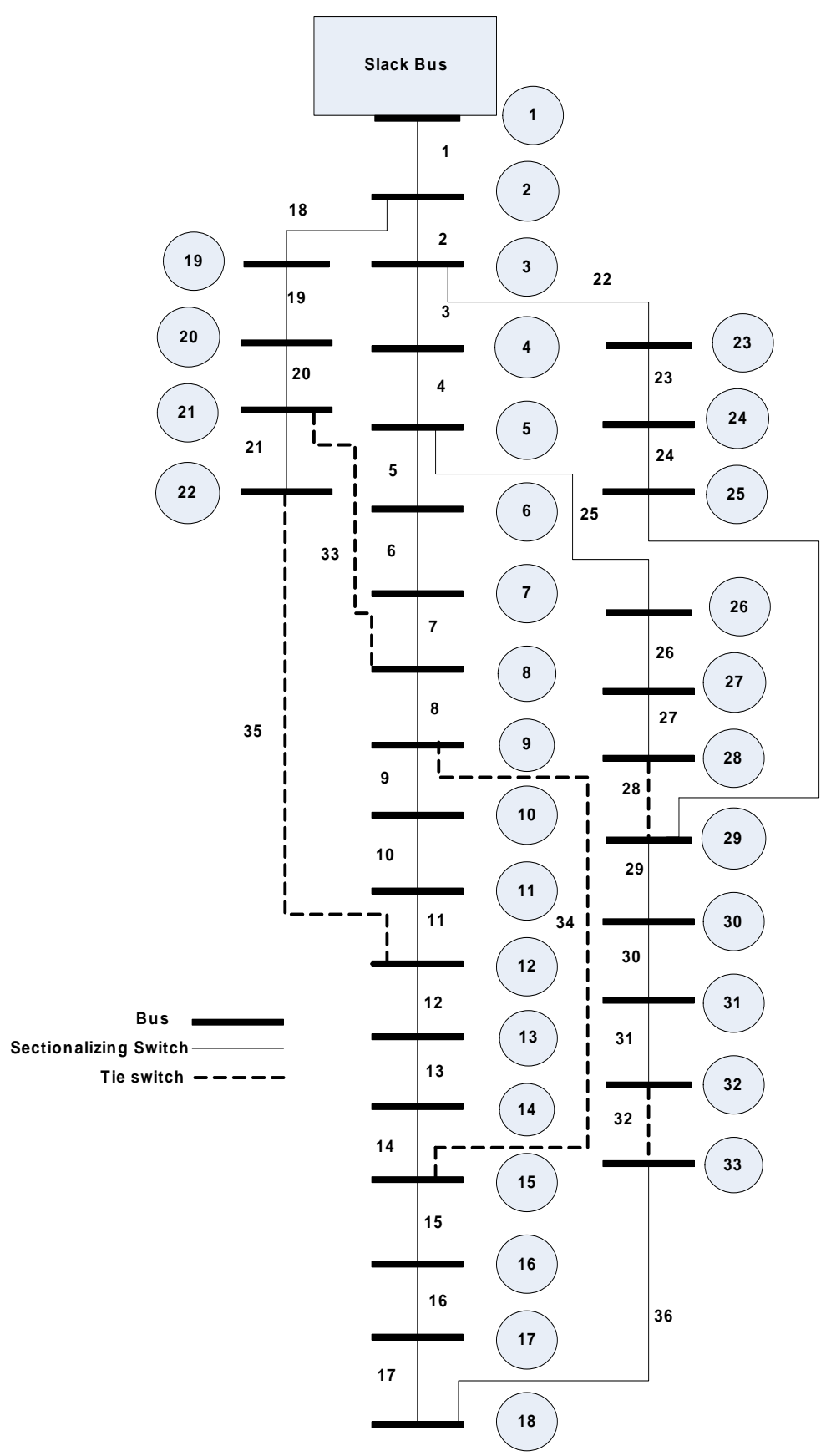

Figure 2. Line diagram of 33-bus RDS after reconfiguration using NRA 1

Table 5. APL and RPL at different tie switches using Algorithm 2

\begin{tabular}{cccccc}
\hline Power Loss & Tie Switch(25-29) & Tie Switch (9-15) & Tie Switch (18-33) & Tie Switch (21-8) & Tie Switch (22-12) \\
\hline Active Power Loss (kW) & 198.75 & 127.1 & 160.88 & 135.25 & 191.86 \\
Reactive Power Loss (kVar) & 132.90 & 90.58 & 130.11 & 98.44 & 162.46 \\
\hline
\end{tabular}




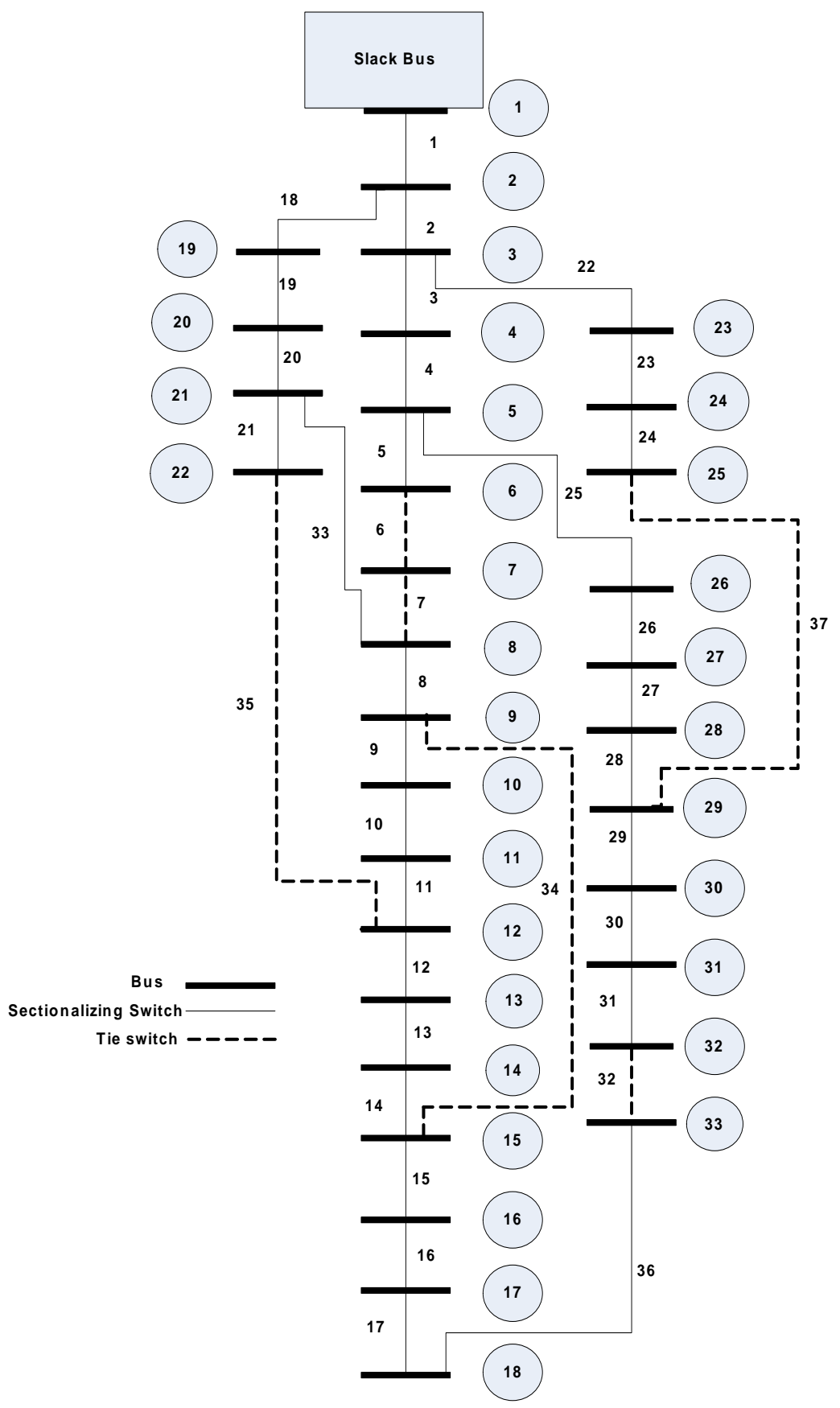

Figure 3. Line diagram of 33-bus RDS after reconfiguration using NRA 2

In NRA 3, the next switch closed is 9-15, then continue the process and open the switch between 14-13. Now the total APL is $147.44 \mathrm{~kW}$. Now close the tie switch18-33, then continue the process and open the switch in between 31-30. The power loss value for this switch is $156.37 \mathrm{~kW}$. The process is repeated till final optimal configuration is obtained. Thus, final total active power loss is $147.44 \mathrm{~kW}$ after reconfiguration with NR Algorithm 3. Power loss values after network reconfiguration Algorithm 3 are given in Table 6.

The line diagram of a re-configured 33 bus RDS employing NRA 3 is shown in Figure 4. The fourth algorithm considers the minimum LSF difference and the sectionalizing transition, which results in the lowest losses. When the base configuration is simulated, the LSF difference tie switch 18-33 is the smallest, thus close this tie switch first. Because the LSF of 18 is smaller than the LSF of 33, the switch between 33 and 32 is opened, and the process of calculating the power loss at each sectionalizing switch continues. The optimum case is a sectionalizing switch that produces the minimum amount of losses. $136.0375 \mathrm{~kW}$ is the optimal power loss. 
Table 6. APL and RPL at different tie switches using Algorithm 3

\begin{tabular}{|c|c|c|c|c|c|}
\hline Power Loss & Tie Switch (25-29) & Tie Switch (9-15) & Tie Switch (18-33) & Tie Switch (22-12) & Tie Switch (21-8) \\
\hline Active Power Loss $(\mathrm{kW})$ & 155.1 & 147.4 & 156.37 & 186.7 & 155.49 \\
\hline Reactive Power Loss (kVar) & 105.7 & 107.6 & 119.56 & 135.1 & 120.16 \\
\hline
\end{tabular}

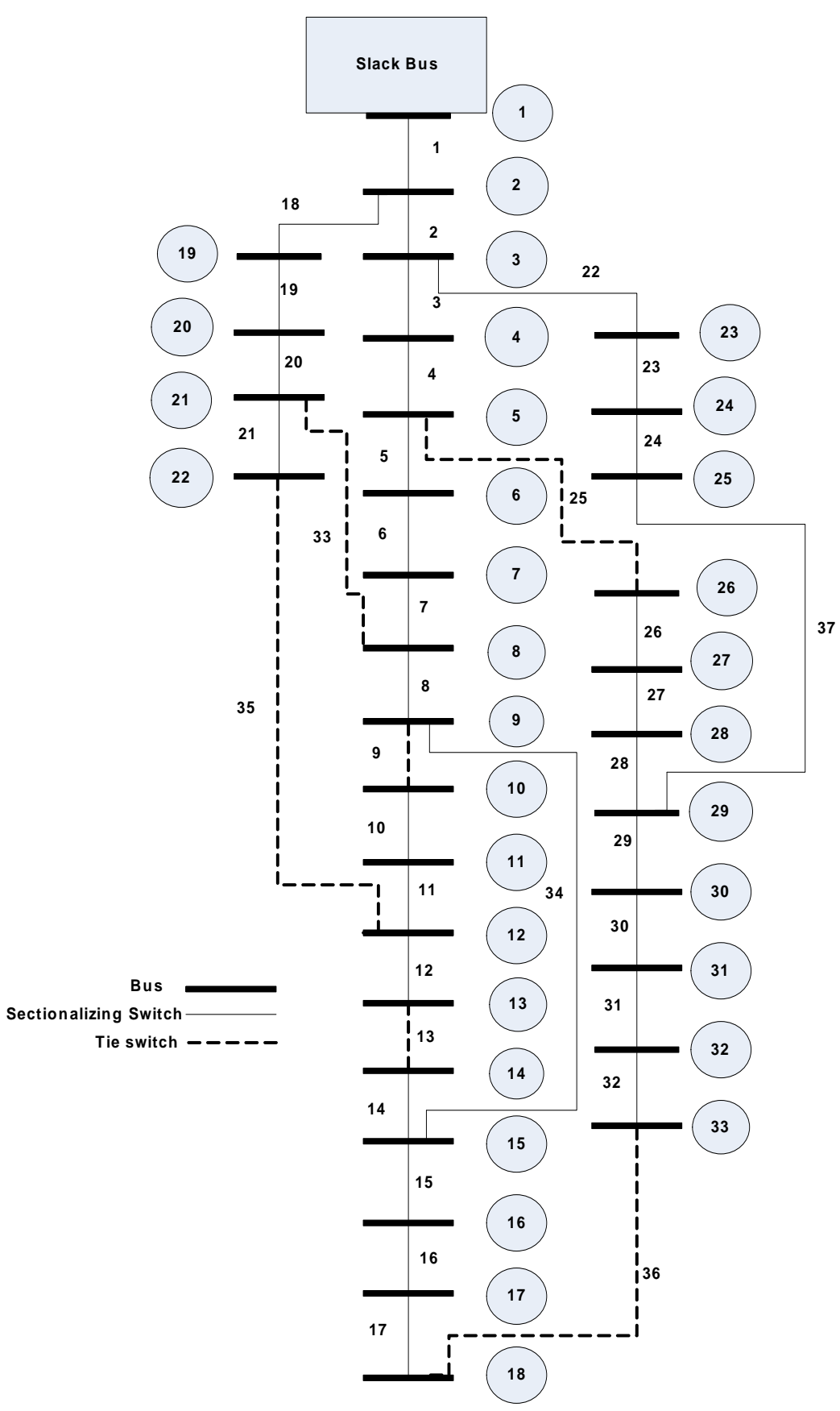

Figure 4. Line diagram of 33-bus RDS after reconfiguration using NRA 3

In this NR, 21-8 tie switch will be closed, then procedure is repeated and the solution is to open the switch in branch 21-20. Now the total APL is $147.129 \mathrm{~kW}$. Tie switch 9-15 is closed next, then continue the process and open the switch in between 13-12. The power loss value for this switch is $134.7413 \mathrm{~kW}$. This process is repeated till final optimal configuration is obtained. Thus, final active power loss is $132.8803 \mathrm{~kW}$ after reconfiguration with NR Algorithm 4. Power loss values after network reconfiguration Algorithm 4 are given in Table 7. Figure 5 represents line diagram of reconfigured 33 bus RDS using NRA 4. 
Power loss values after NR of four considered algorithms are given in Table 8 respectively. The optimized case is compared with the literature in [30] which shows that the considered algorithm performs better when compared to literature. Figure 6 represents the comparative analys is of all the four considered NR algorithms with their active and reactive power losses. From Table 8, it can be observed that from all the considered NR algorithms NRA 2 shows the better performance when compared with other NRA's. So it can be concluded that NRA 2 gives the optimized performance when compared with the literature [30].

Table 7. APL and RPL at different tie switches using Algorithm 4

\begin{tabular}{|c|c|c|c|c|c|}
\hline Power Loss & Tie Switch (18-33) & Tie Switch (21-8) & Tie Switch (22-12) & Tie Switch (9-15) & Tie Switch (25-29) \\
\hline Active Power Loss $(\mathrm{kW})$ & 136.0 & 147.1 & 134.7 & 150.8 & 132.8 \\
\hline Reactive Power Loss (kVar) & 105.7 & 107.0 & 118.0 & 123.4 & 117.2 \\
\hline
\end{tabular}

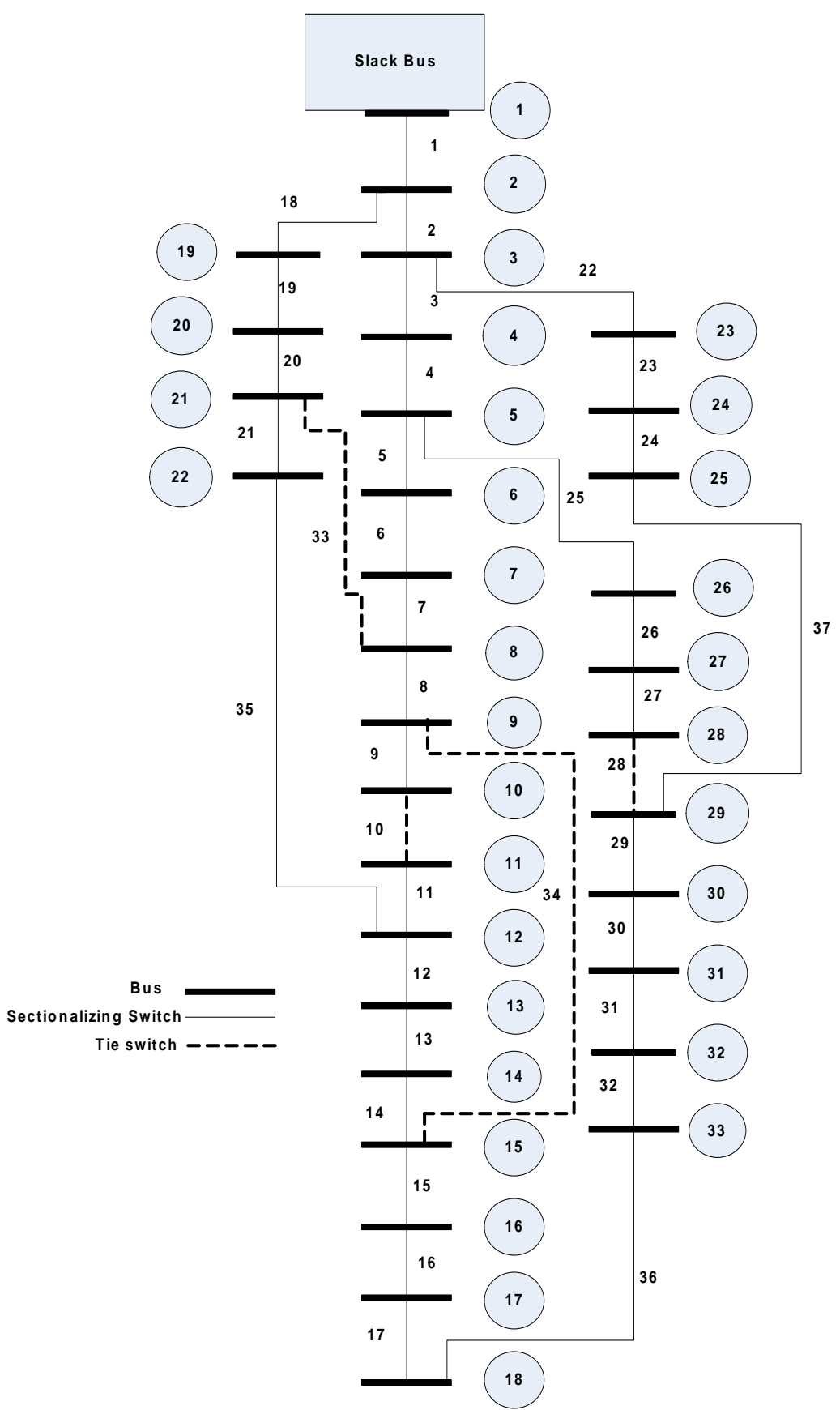

Figure 5. Line diagram of 33-bus RDS after reconfiguration using NRA 4 
Table 8. Comparison of APL and RPL using different algorithms

\begin{tabular}{ccccc}
\hline Power Loss & NRA 1 [30] & NRA 2 & NRA 3 & NRA 4 [31] \\
\hline Active Power Loss (kW) & 137.53 & 127.1 & 147.4 & 132.8 \\
Reactive Power Loss (kVar) & 113.48 & 90.5 & 107.6 & 117.2 \\
\hline
\end{tabular}

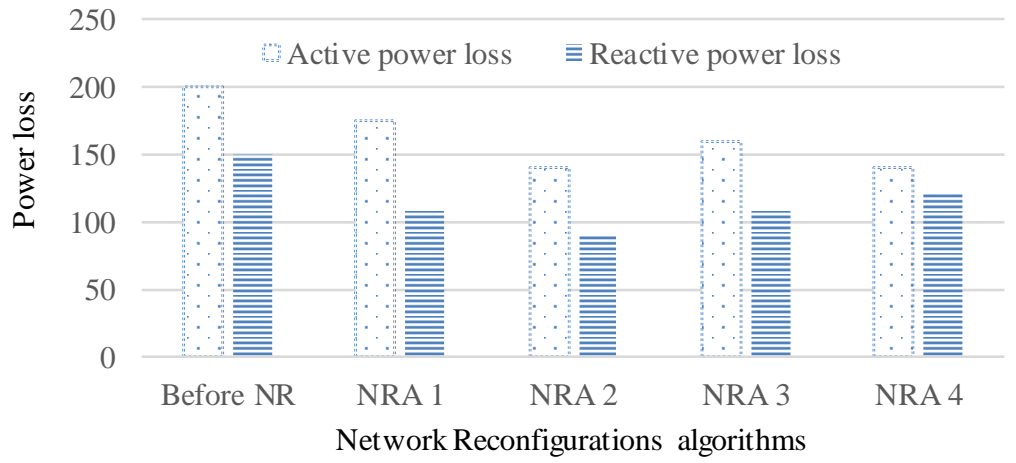

Figure 6. APL and RPL before and after NR

\subsection{Reliability analysis}

Reliability indices are calculated by using the cutest approach at load points. These indices with and without NR are represented in Table 9. Figure 7 shows the comparison of reliability indices before and after NR1, NR 2, NR 3, and NR 4. Hence from Figure 7 and Table 9 it can be concluded that the reliability indices for NRA 2 is better when compared to the remaining NR algorithms.

Table 9. Comparis on of reliability indices before and after NR

\begin{tabular}{ccccccc}
\hline S. No. & Index & Before NR & After NR1 & After NR 2 & After NR 3 & After NR 4 \\
\hline 1 & SAIFI & 2.41 & 2.29 & 2.18 & 2.65 & 2.80 \\
2 & SAIDI & 2.04 & 2.02 & 1.67 & 1.92 & 2.06 \\
3 & CAIDI & 0.84 & 0.88 & 0.76 & 0.72 & 0.73 \\
4 & ASAI & 0.99 & 0.99 & 0.99 & 0.99 & 0.99 \\
5 & ASUI & $2.3 \mathrm{e}-04$ & $2.3 \mathrm{e}-04$ & $1.9 \mathrm{e}-04$ & $2.1 \mathrm{e}-04$ & $2.3 \mathrm{e}-04$ \\
\hline
\end{tabular}

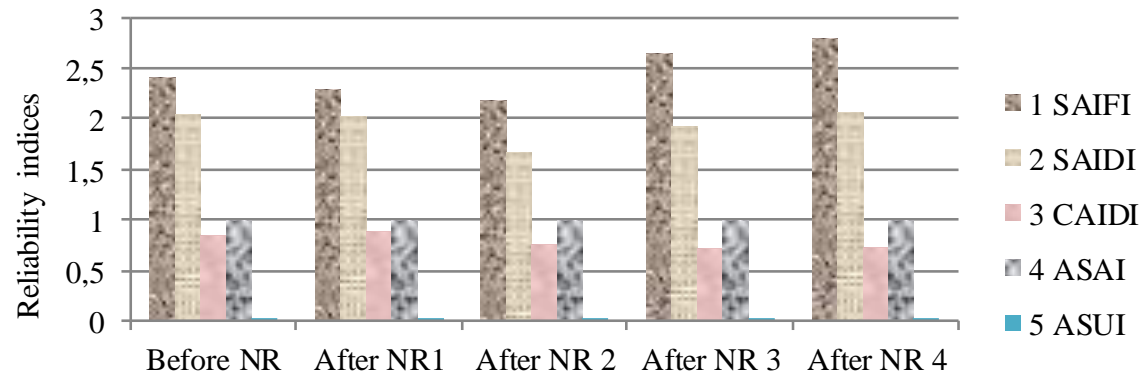

Network Reconfiguration algorithms

Figure 7. Reliability indices before and after NR

\section{CONCLUSION}

This paper presents a brief analysis on various network reconfiguration algorithms that work on LSF condition for switching action of tie switch and sectionalizing switch to reconfigure the network without changing its radial nature. Here, among the considered algorithms, Algorithm 2 with minimum LSF difference, considering only adjacent sectionalizing switch gives the optimal solution. The algorithms are implemented using MATLAB environment and arrived at minimum loss and better reliability performance when compared to literature.

Int J Elec \& Comp Eng, Vol. 12, No. 2, April 2022: 1199-1210 


\section{REFERENCES}

[1] M. E. Baran and F. F. Wu, "Network reconfiguration in distribution systems for loss reduction and load balancing," IEEE Transactions on Power Delivery, vol. 4, no. 2, pp. 1401-1407, Apr. 1989, doi: 10.1109/61.25627.

[2] B. Sultana, M. W. Mustafa, U. Sultana, and A. R. Bhatti, "Review on reliability improvement and power loss reduction in distribution system via network reconfiguration," Renewable and Sustainable Energy Reviews, vol. 66, pp. 297-310, Dec. 2016 , doi: 10.1016/j.rser.2016.08.011

[3] A. M. Imran and M. Kowsalya, "A new power system reconfiguration scheme for power loss minimization and voltage pr ofile enhancement using fireworks algorithm," International Journal of Electrical Power and Energy Systems, vol. 62, p p. 312-322, Nov. 2014, doi: 10.1016/j.ijepes.2014.04.034.

[4] R. J. Sarfi, M. M. A. Salama, and A. Y. Chikhani, “A survey of the state of the art in distribution sy stem reconfiguration for system loss reduction," Electric Power Systems Research, vol. 31, no. 1, pp. 61-70, Oct. 1994, doi: 10.1016/03787796(94)90029-9.

[5] B. Enacheanu, B. Raison, R. Caire, O. Devaux, W. Bienia, and N. HadjSaid, "Radial network rec onfiguration using gen et ic algorithm based on the matroid theory," IEEETransactions on Power Systems, vol. 23, no. 1, p p. 186-195, Feb. 2008, do i: 10.1109/TPWRS.2007.913303.

[6] A. C. Santos, A. C. B. Delbem, J. B. A. London, and N. G. Bretas, "Node-depth encoding and mult iobjective ev olutionary algorithm applied to large-scale distribut ion system reconfiguration,"IEEETransactions on Power Systems, vol. 25, no. 3, pp. 1254-1265, Aug. 2010, doi: 10.1109/TPWRS.2010.2041475.

[7] A. K. Ferdavani, A. A. bin Mohd Zin, A. bin Khairuddin, and M. M. Naeini, "A review on reconfiguration of radial electric al distribution network through heuristic methods," in 2011 Fourth International Conference on Modeling, Simulation and App lied Optimization, Apr. 2011, pp. 1-5, doi: 10.1109/ICMSAO.2011.5775464.

[8] M. S. T sai and F. Y. Hsu, "Application of grey correlation analysis in evolutionary programming for distribution sy stem fee de $\mathrm{r}$ reconfiguration," IEEE Transactions on Power Systems, vol. 25, no. 2, pp. 1126-1133, May 2010, doi: 10.1109/TPWRS.2009.2032325.

[9] A. Swarnkar, N. Gupta, and K. R. Niazi, "Distribution network reconfiguration using population -based AI techniques: a comparative analysis," in 2012 IEEE Power and Energy Society General Meeting, Jul. 2012, pp. 1-6, doi: 10.1109/PESGM.2012.6345013.

[10] M. Lavorato, J. F. Franco, M. J. Rider, and R. Romero, "Imposing radiality constraints in distribution sy stem optimization problems," IEEE Transactions on Power Systems, vol. 27, no. 1, pp. 172-180, Feb. 2012, doi: 10.1109/TPWRS.201 1.2161349.

[11] L. S. M. Guedes, A. C. Lisboa, D. A. G. Vieira, and R. R. Saldanha, "A multiobjective heuristic for reconfiguration of the electrical radial network," IEEE Transactions on Power Delivery, vol. 28, no. 1, pp. 311-319, Jan. 2013, doi: 10.1109/TPWRD.2012.2218260.

[12] S. Kalambe and G. Agnihotri, "Loss minimization techniques used in distribution network: Bibliographical survey," Ren ewa ble and Sustainable Energy Reviews, vol.29,pp. 184-200, Jan. 2014, doi: 10.1016/j.rser.2013.08.075.

[13] H.-D. Chiang and J.-C. Wang, "System for achieving optimal steady state in power distribution networks." USPatent 5734586 , 1998.

[14] T. Sawa, T. Furukawa, and T. Onishi, “Creation method and apparatus of network configuration for power system.” US P at ent 6181984, 2001.

[15] A. M. G. Solo, R. J. Sarfi, and R. Gokaraju, "Network radiality in reconfiguration of a radial power distribution sy st em usin g a matrix structured knowledge based system."USPatent 288118,2008

[16] A. C. Biswal, A. Mangla, R. Jha, and A. Rahman, "System and method for real-time feeder reconfiguration for load balancing in distribution system automation." WIPO Patent 1033, 2015.

[17] F. Yang, J. Stoupis, and V. Donde, "Feeder aut omation for an electric power distribution system.” USPatent 8121740, 2021.

[18] D. Q. Hung, N. Mithulananthan, and R. C. Bansal, "Integration of PV and BES units in commercial distribution systems considering energy loss and voltage stability," Applied Energy, vol. 113, pp. 1162-1170, Jan. 2014, doi: 10.1016/j.apenergy.2013.08.069.

[19] J. Hivziefendic, A. Hadžimehmedovic, and M. Tešanovic, "Optimal network reconfiguration with distributed gen er ation using NSGA II algorithm," International Journal of Advanced Research in Artificial Intelligence, vol. 5, no. 2, 2016, doi: 10.14569/IJARAI.2016.050202.

[20] B. Amanulla, S. Chakrabarti, and S. N. Singh, "Reconfiguration of power distribution systems considering reliability an d po we r loss," IEEE Transactions on Power Delivery, vol. 27, no. 2, pp. 918-926, Apr. 2012, doi: 10.1 109/TPWRD.2011.2179950.

[21] A. Swarnkar, N. Gupta, and K. R. Niazi, "Adapted ant colony optimization for efficient reconfiguration of balanced and unbalanced distribut ion systems for loss minimization," Swarm and Evolutionary Computation, vol. 1, no.3, pp. 129-137, Sep. 2011, doi: 10.1016/j.swevo.2011.05.004

[22] M. M. Eusuff and K. E. Lansey, "Optimization of water distribution network design using the shuffled frog leaping a lgo rithm," Journal of Water Resources Planning and Management, vol. 129, no.3, pp. 210-225, May 2003, do i: 10.1061/(asce)07339496(2003) 129:3(210).

[23] T. Niknam and E. Azad Farsani, "A hybrid self-adaptive particle swarm optimization and modified shuffled frog leaping algorithm for distribution feeder reconfiguration," Engineering Applications of Artificial Intelligence, vol. 23, no. 8, pp. 1340-1349, Dec. 2010, doi: 10.1016/j.engappai.2010.02.005.

[24] B. Arandian, R. A. Hooshmand, and E. Gholipour, "Decreasing activity cost of a distribution system company by reconfiguration and power generat ion control of DGs based on shuffled frog leaping algorithm," International Journal of Electrical Power and Energy Systems, vol. 61, pp. 48-55, Oct. 2014, doi: 10.1016/j.ijepes.2014.03.001.

[25] W. Zheng, W. Huang, and D. J. Hill, "A deep learning-based general robust method for network reconfiguration in th ree -p ha se unbalanced active distribution networks," International Journal of Electrical Power and Energy Systems, vol. 12 0, Sep. 2020, Art. no. 105982, doi: 10.1016/j.ijepes.2020.105982.

[26] Y. Gao, J. Shi, W. Wang, and N. Yu, "Dynamic distribution network reconfiguration using reinforcement learning," in 2019 IEEE International Conference on Communications, Control, and Computing Technologies for Smart Grids (SmartGridComm), Oct. 2019, pp. 1-7, doi: 10.1109/SmartGridComm.2019.8909777.

[27] J. H. Teng, "A direct approach for distribution system load flow solutions," IEEE Transactions on Power Delivery, vol. 18, no. 3, pp. 882-887, Jul. 2003, doi: 10.1109/TPWRD.2003.813818.

[28] P. S. Devi, D. R. Kumar, and C. Kiran, "Loss minimization and reliability enhancement in electrical power distribution sy stems using net work reconfiguration with loss sensitivity factor," in 2021 2nd International Conference for Emerging Technology (INCET), May 2021, pp. 1-6, doi: 10.1109/INCET51464.2021.9456167. 
[29] R. S. Rao, K. Ravindra, K. Satish, and S. V. L. Narasimham, "Power loss minimization in distribution sy stem using net wo rk reconfiguration in the presence of distributed generation," IEEETransactions on Power Systems, vol. 28, no. 1, pp. 317-325, Feb. 2013, doi: 10.1109/TPWRS.2012.2197227.

[30] R. Billinton and R. N. Allan, Reliability evaluation of power systems. Boston, MA: Springer US, 1996.

[31] G. S. Kumar, S. S. Kumar, and S. V. J. Kumar, "Reconfiguration of electrical distribution network for loss reduction and vol tage enhancement," in IEEE International Conference on Power, Control, Signals and Instrumentation Engineering, ICPCSI 2017 , Sep. 2018, pp. 1387-1392, doi: 10.1109/ICPCSI.2017.8391939.

\section{BIOGRAPHIES OF AUTHORS}

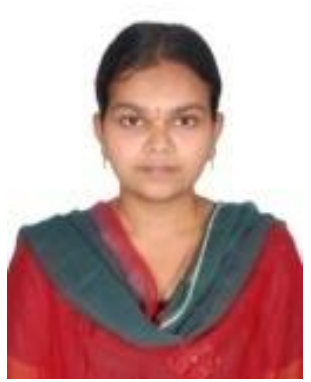

Parasa Sushma Devi ${ }^{(D)}$ SC $\mathrm{P}$ graduated in Electrical and Electronics Engineering from Andhra Loyola Institute of Engineering and Technology, Vijay awada, Andhra Pradesh, India in 2013. She got M.Tech. In Power Systems Control and Automation from PVP Siddhartha Institute of Engineering and Technology, Vijay awada, Andhra Pradesh, India. She is currently pursuing Ph.D. in VNR Vignana Jyothi Institute of Engineering and Technology, Hyderabad, Telangana. She can be contacted at email: sush1634@gmail.com.

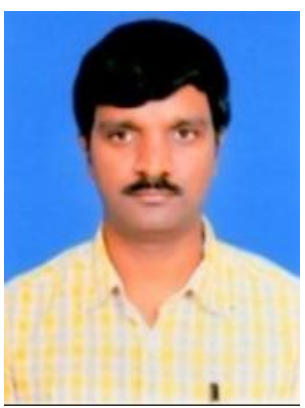

Dasari Ravi Kumar (iD 81 SC P completed his B.Tech. in EEE in 2006 and M.Tech. in Power Systems from JNTU, Hyderabad in 2008 and Ph.D. in Electrical Engineering from JNTU Anantapur in 2017. He has 13 Years of teaching experience. He has published 30 research papers in International, National Journals and Conferences. He visited Singapore and presented a paper in IEEE International Conference ICBEST-2015 at CREATE, Singapore. Some of his papers are Indexed by Scopus and Web of Science. His Patent titled "A Passive filter configuration to reduce THD produced by Non-Linear loads" was published in patent office journal, issue No:51/2012 and is in amended stage now. He has executed UGC Minor Research Project on "Development of Optimization Techniques for Protective Devices and Distributed Generators allocation to optimize Reliability and to reduce losses in Electrical Power Distribution systems with a sanctioned amount of Rs. 4.95 Lakhs". He is currently working as an Associate Professor in the Department of Electrical and Electronics Engineering and JNTUH, AICTE Coordinator of VNR Vignana Jyothi Institute of Engineering and Technology, Hyderabad, India. He can be contacted at email: ravikumar_d@ vnrvjiet.in.

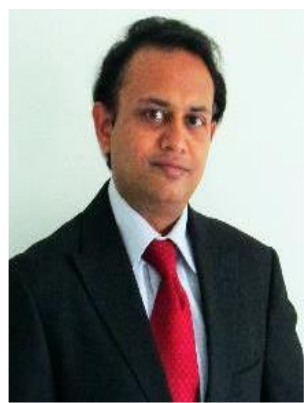

Kiran Chakravarthula (iD SC SC P completed his Bachelor of Technology in 1999 in Electronics and Instrumentation, Master of Science in 2010 Applied Physics, Master of Science Microsystems Engineering in 2007, Microsystems Engineering, Master of Science Engineering 2006 Biomedical Engineering and Ph.D. (Engineering) 2012 in Engineering Physics. He published many national and international journal papers. His research interests are sensors, virtual instrumentation, internet of things, data sciences, assistive technologies, biomedical sensors, biomedical imaging, high energy physics, particle physics, quantum chromo dy namics (QCD), microsy stems, nanotechnology, MEM S/NEMS, protein engineering, biochemistry, Nano biotechnology. He is currently working as an associate professor in the Department of Electronics and Instrumentation Engineering, VNR Vignana Jy othi Institute of Engineering and Technology, Hyderabad, India. He can be contacted at email: kiran_c@vnrvjiet.in. 